\title{
Emissões Atmosféricas provenientes de Incêndios com Derivados de Petróleo e sua contribuição para o efeito estufa
}

\section{Atmospheric Emissions from Oil Based Fires and their contribution to the greenhouse effect}

DOI: 10.46814/lajdv3n1-010

Recebimento dos originais: 30/10/2020

Aceitação para publicação: 11/01/2021

\author{
Jeferson Cerqueira Dias \\ Mestrado \\ Universidade de São Paulo - USP
}

Faculdade de Tecnologia do Estado de São Paulo - FATEC

Avenida Professor Luciano Gualberto, 374 - Butantã - São Paulo - SP

\author{
Jônatas Cerqueira Dias \\ Mestrado \\ Universidade de São Paulo - USP \\ Faculdade de Tecnologia do Estado de São Paulo - FATEC \\ Avenida Professor Luciano Gualberto, 374 - Butantã - São Paulo - SP \\ Jumara Aparecida Batista Gonçalves \\ Especialização \\ Universidade de São Paulo - USP \\ Faculdade de Tecnologia do Estado de São Paulo - FATEC \\ Avenida Professor Luciano Gualberto, 374 - Butantã - São Paulo - SP \\ Guilherme Fogaça Colamaria \\ Tecnólogo \\ Faculdade de Tecnologia do Estado de São Paulo - FATEC
}

\begin{abstract}
RESUMO
O objetivo desse trabalho foi estabelecer uma metodologia para calcular inventários de emissões atmosféricas para incêndios em petróleo e óleo diesel. Para isso, foi proposta uma metodologia, através da aplicação de uma fórmula para calcular a emissão de poluentes com base no volume de combustível, fator de emissão de cada combustível e densidade do combustível. Para aplicação prática foram usados volumes de quatro tanques do tipo API, dos mais usados para armazenamento destes produtos e os resultados foram apresentados em uma tabela. Para poder realizar a comparação e observação dos impactos foi realizado pesquisa para levantamento dados de emissões atmosféricas veiculares para o estado de São Paulo realizado pela CETESB. Pelos resultados gerados, apresentados na Tabela 1, percebe-se que as emissões de incêndio de petróleo e óleo diesel, conforme o tamanho do tanque, são bastante significativas, quando comparados em uma escala diária, e levando-se em conta que as emissões de incêndios são locais e as emissões veiculares utilizadas são para todo o Estado de São Paulo. Neste sentido, uma continuidade de pesquisas para definição de fatores de emissões para todos os poluentes atmosféricos gerados em incêndios contribuiriam para a prevenção dos efeitos à saúde causados por estes sinistros.
\end{abstract}


Palavras-chaves: emissões por incêndio, inventário de emissões, fatores de emissão, efeitos à saúde.

\begin{abstract}
The objective of this work was to establish a methodology to calculate inventories of atmospheric emissions for fires in oil and diesel oil. For this, a methodology was proposed, through the application of a formula to calculate the emission of pollutants based on the volume of fuel, emission factor of each fuel and fuel density. For practical application, volumes of four API type tanks were used, the most used for storage of these products and the results were presented in a table. In order to carry out the comparison and observation of the impacts, a survey of vehicular atmospheric emissions for the state of São Paulo was conducted by CETESB. From the results generated, presented in Table 1, it can be seen that the oil and diesel fire emissions, according to the size of the tank, are quite significant, when compared on a daily scale, and taking into account that the fire emissions are local and the vehicular emissions used are for the whole State of São Paulo. In this sense, a continuity of research to define emission factors for all air pollutants generated by fires would contribute to the prevention of health effects caused by these accidents.
\end{abstract}

Keywords: fire emissions, emissions inventory, emission factors, health effects.

\title{
1 INTRODUÇÃO
}

Todos os combustíveis fósseis contêm carbono, onde o petróleo se baseia e, dentro do seu ciclo geoquímico é responsável pela produção de dióxido de carbono, dentre outros (SPEIGHT, 2014). Quando esses combustíveis são queimados, a menos que o carbono resultante seja capturado, ele é liberado para a atmosfera na forma de dióxido de carbono, quando a reação química é completa, o que significa que é um contribuinte para o que é popularmente conhecido como efeito estufa, o qual contribui para o aquecimento global (MMA, 2018; UNEP, 2020). Embora o dióxido de carbono seja o mais abundante e mais estudado dos gases do efeito estufa, muitos outros têm propriedades de radiação térmica semelhantes, no entanto em menores volumes. Estes incluem os clorofluorcarbonos, óxido nitroso, dióxido de enxofre e metano (TIETENBERG; LEWIS, 2018).

As emissões atmosféricas dos gases do efeito estufa são originadas da queima de combustíveis fósseis e biomassa, dentre outras fontes que passaram a ser inventariadas para um diagnóstico de causas e os controles necessários para a sua redução (NI et al., 2014; TIETENBERG; LEWIS, 2018).

As emissões globais de $\mathrm{CO} 2$ provenientes dos combustíveis fósseis e da indústria são a principal fonte de emissões globais de gases de efeito estufa (UNEP, 2019). Atualmente, representam cerca de 78 por cento das emissões globais de gases com efeito de estufa, e foram estimadas num total de 52,4 GtCO2 para 2019 (UNEP, 2020). Foram estabelecidos cálculos de emissões para fontes fixas e móveis, através de protocolos elaborados pela Agência de Proteção Ambiental nos Estados Unidos e a Agência Ambiental na Inglaterra, a partir das quais, o Brasil desenvolveu as suas diretrizes para o cálculo de emissões (CETESB, 2014; CETESB, 2020a). O Ministério do Meio Ambiente estabeleceu legislação 
pertinente para definição dos poluentes atmosféricos, através do CONAMA, assim como, em São Paulo, a legislação estadual estabeleceu e revisou seus parâmetros para poluentes atmosféricos, com aplicação através da Companhia de Tecnologia do Estado de São Paulo, CETESB (CONAMA, 2011; MMA, 2018).Grande parte da legislação está dedicada aos cálculos de emissão para fontes móveis veiculares (automóveis, caminhões e motocicletas), e fontes fixas estacionárias (chaminés). Entretanto, quase nada há relacionado ao cálculo de emissões atmosféricas para incêndios, e principalmente, incêndios em derivados de petróleo (HUSAIN, 1996; SHAREEF; HUSAIN; ALHARBI, 2016),

No Brasil existem registros de incêndios em processos petroquímicos, no entanto, não se encontra registros de inventário ou cálculo de emissões decorrentes de incêndios com petróleo ou derivados. Alguns estudos têm sido realizados com a queima em ambientes abertos de petróleo e derivados, o que nos permite conhecer um pouco mais da dimensão destes impactos ambientais pelas emissões atmosféricas de MP, NOx, CO, SOx, Gases do Efeito Estufa (GEE) dentre outros (LEMIEUX; LUTES; SANTOIANNI, 2004; SHAREEF; HUSAIN; ALHARBI, 2016; GULLETT et al., 2017; KUMAR et al., 2020).

O objetivo deste estudo é estabelecer uma metodologia para calcular inventários de emissões atmosféricas para incêndios em petróleo e óleo diesel. Os objetivos específicos são: (i) levantar os fatores de emissões, densidades e os volumes de tanques existentes para petróleo e óleo diesel, através de pesquisa bibliográfica; (ii) levantar informações emissões atmosféricas veiculares, através de pesquisa bibliográfica; (iii) desenvolver uma fórmula matemática para o cálculo de emissões para incêndios; (iv) elaborar uma tabela com os resultados calculados com a fórmula desenvolvida; e (v) comparar as emissões veiculares atmosféricas e as emissões para incêndios com petróleo e óleo diesel.

A justificativa se dá pela grande carga de emissões atmosféricas por incêndios em tanques de armazenamento de produtos químicos derivados de petróleo e a necessidade de se tomar ações de prevenção de intoxicação da população local e outras populações no alcance dos efeitos das emissões atmosféricas destes incêndios. Assim, os municípios que possuem este tipo de indústria poderiam prever ou cobrar planos de ações emergenciais mais efetivos com recursos suficientes as dimensões destas emergências.

\section{REFERENCIAL TEÓRICO}

No Relatório de Emissões Veiculares da CETESB, emitido em 2020, são indicados os principais poluentes originados na combustão de motores de automóveis comerciais leves, motocicletas e veículos a Diesel, conforme Tabela 1. A combustão em motores é uma queima de combustível em um ambiente controlado, pois, pode-se regular a entrada de combustível e oxigênio na câmara de combustão. Assim, a reação tende a ser mais eficaz com redução de poluentes indesejados pela 
combustão incompleta, quando não se oxida ao máximo um elemento. Por exemplo, o dióxido de carbono (CO2) é o resultado de uma oxidação completa. No entanto, o monóxido de carbono (CO), e o material particulado, carbono (C) são resultados de oxidações incompletas. Este mesmo processo, também, pode acontecer com o dióxido de enxofre (SO2), e o dióxido de nitrogênio (NO2) (CETESB, 2020b).

O material particulado (MP10, MP2.5) é uma mistura complexa de sólidos com diâmetros reduzidos. Originado na queima de combustíveis fósseis, e emissões decorrentes de obras e pavimentação de vias. Os efeitos sobre a saúde incluem: câncer respiratório, inflamação de pulmão, agravamento de sintomas de asma, aumento de internações hospitalares e podem levar à morte. O monóxido de carbono (CO) é um gás inodoro e incolor, formado no processo de queima de combustíveis incompleta, sendo a maior parte das emissões em áreas urbanas decorrentes dos veículos automotores. Os efeitos estão relacionados com a fadiga e dor no peito, e em alta concentração pode levar a asfixia e morte (MMA; MS; MC, 2009; CONAMA, 2011; MMA, 2018).

O inventário de emissões atmosféricas é um conjunto de dados obtidos a partir de fontes de poluição, especificadas numa dada área geográfica e num dado período de tempo (CETESB, 2020). Em 2019, no Estado de São Paulo, estimou-se que foram emitidas 299.118 mil toneladas de CO, 62.693 mil toneladas de NMHC, 164.859 mil toneladas de NOx, 4.148 mil toneladas de MP, 2.712 mil toneladas de SO2 e 1,6 mil toneladas de aldeídos, todos poluentes tóxicos, 1.895 mil toneladas de RCHO, e 38.495 toneladas de GEE (CETESB, 2020).

Numa escala global, os maiores emissores de GEE são a China com 14.0 GtCO2, os Estados Unidos com 6.2 GtCO2, a União Européia com 4.6 GtCO2 (UNEP, 2020). Está claro que estas são emissões de fontes móveis e fixas, mas que são aqui analisadas para que possibilitem a dimnsão do impacto dos incêndios em petróleos e derivados.

Para uma melhor caracterização das emissões decorrentes de incêndio em líquidos inflamáveis, pesquisas realizadas por Booher e Jacke (1997), e posteriormente, revisadas pela Agência Ambiental Inglesa em 2009, extraíram amostras do ambiente, para as emissões de hidrocarbonetos, a partir da queima controlada de 500 galões de petróleo bruto e óleos combustíveis, em grandes tanques abertos (AQMAU, 2009). Um galão é equivale a 3,78 litros, totalizando 1.890 litros. A partir deste experimento foram identificadas taxas de emissões de vários compostos químicos e elaborada a Tabela 1. A maior parte do carbono gerado em incêndios de hidrocarbonetos é emitida como: CO2 (92\%), CO (3\%) e C (5\%). Menores quantidades decompostos orgânicos voláteis não queimados $(<1 \%)$, aldeídos e cetonas (<1\%), NOx e SOx são também emitidos. Não foram detectados metais, (AQMAU, 2009).

A Tabela 1 indica os fatores de emissão para queima controlada de óleo diesel. 
Tabela 1 - Fatores de emissão (g/kg) provenientes da queima de diesel vermelho (Booher e Janke, 1997).

\begin{tabular}{c|c|c|c|c}
\hline $\begin{array}{c}\text { NOx como } \\
\text { NO2 }\end{array}$ & PM10 & CO & SO2 & $\begin{array}{c}\text { Benzeno (como } \\
\text { VOC) }\end{array}$ \\
\hline 2,4 & 0,22 & 0,61 & 2,22 & no \\
\hline
\end{tabular}

Fonte: adapatado de Booher e Jake, 1997

\section{METODOLOGIA}

A metodologia a ser utilizada neste trabalho, está relacionada, à revisão bibliográfica e metodológica, para desenvolvimento de uma fórmula para os cálculos de emissões em incêndios com petróleo e seus derivados. Será realizada a aplicação dos cálculos de emissões atmosféricas para os volumes de combustíveis de pequenos, médios e grandes tanques, padrão API, de alguns produtos inflamáveis, como: petróleo bruto e óleo diesel, e a comparação entre os volumes de emissões destas fontes de incêndio com as emissões atmosféricas veiculares anuais no Estado de São Paulo, dos poluentes: dióxido de carbono (CO2), monóxido de carbono $(\mathrm{CO})$, material particulado $(\mathrm{C})$ no ano de 2019 (CETESB, 2020a), e nacional, referente ao ano de 2010, (CONAMA, 2011).

Para o cálculo das emissões atmosféricas para incêndios em petróleo e seus derivados, o princípio é o mesmo utilizado pela CETESB, no entanto com uma leve adequação, representada na Equação 1. Onde as emissões atmosféricas são obtidas a partir da multiplicação do volume $\left(\mathrm{m}^{3}\right)$ do combustível pela densidade $\left(\mathrm{kg} / \mathrm{m}^{3}\right)$ do combustível envolvido no evento, e multiplicado pelo fator de emissão $(\mathrm{g} / \mathrm{kg})$ dos poluentes gerados no combustível que estiver no incêndio.

Assim,

$$
\mathrm{Ei}=\mathrm{Ci} \times \mathrm{di} \times \mathrm{Fep} \quad \text { (Equação 1) }
$$

Onde:

Ei Massa de poluente emitida no evento considerado para o combustível "i” (g/evento);

$\mathrm{Ci} \quad$ Volume do combustível envolvido no evento $\left(\mathrm{m}^{3}\right)$;

di densidade específica do combustível “i” $\left(\mathrm{kg} / \mathrm{m}^{3}\right)$;

Fep Fator de emissão que depende do tipo de poluente e combustível envolvido.

\subsection{ANÁLISE DE DADOS}

Foi adotado para este trabalho o método quantitativo com a tabulação de dados gerados a partir da aplicação da Equação 1, proposta no item 3, metodologia.

\section{RESULTADOS}

Os valores dos fatores de emissão, densidade e volume para o petróleo bruto e óleo diesel, conforme definidos no item 2, foram extraídos de referências bibliográficas. A Tabela 2 apresenta uma 
amostra de volumes que representam alguns tanques padrão API 650, mais utilizados, e pelo menos um de grande volume. Foram escolhidos tanques de $5.404 \mathrm{~m}^{3}, 10.764 \mathrm{~m}^{3}, 26.687 \mathrm{~m}^{3}$ e $120.092 \mathrm{~m}^{3}$. Foi estimado um volume operacional de $70 \%$ do volume de projeto dos quais foram obtidos respectivamente, $3.872,8 \mathrm{~m}^{3}, 7.534,8 \mathrm{~m}^{3}, 18.680,9 \mathrm{~m}^{3}$ e $84.064,4 \mathrm{~m}^{3}$. As densidades são de $825 \mathrm{~kg} / \mathrm{m}^{3}$ para petróleo bruto e de $820 \mathrm{~kg} / \mathrm{m}^{3}$ para o óleo diesel. Os fatores de emissão utilizados para o petróelo crú são: do monóxido de carbono, 30 g/kg, e material particulado, 70 g/kg, (LEMIEUX, 2004). Os fatores de emissão para os poluentes do óleo diesel são: $0,6 \mathrm{~g} / \mathrm{kg}$ de monóxido de carbono, $0,22 \mathrm{~g} / \mathrm{kg}$ do material particulado, 2,4 g/kg do dióxido de nitrogênio, e 2,22 g/kg do dióxido de enxofre, (AQMAU, 2009). Os resultados para os poluentes do óleo Diesel, com as emissões atmosféricas do menor e do maior tanque, as quais foram de $1.892 \mathrm{~kg}$ e $42.049 \mathrm{~kg}$ para o monóxido de carbono; de 682 kg e $15.165 \mathrm{~kg}$ para o material particulado; de $7.445 \mathrm{~kg}$ e $165.439 \mathrm{~kg}$ para o dióxido de nitrogênio; e de $6.886 \mathrm{~kg}$ e $153.031 \mathrm{~kg}$ para o dióxido enxofre, respectivamente. Para os poluentes do petróleo bruto, as emissões atmosféricas do menor e do maior tanque foram de $93.624 \mathrm{~kg}$ e $2.080 .594 \mathrm{~kg}$ para monóxido de carbono; e de $530.538 \mathrm{~kg}$ e $11.790 .032 \mathrm{~kg}$ para material particulado, respectivamente. Para o petróleo bruto as emissões de dióxido de carbono do menor e do maior tanque foram 9.761 .894 kg e $216.936 .591 \mathrm{~kg}$. E para o óleo Diesel, as emissões atmosféricas de dióxido de carbono do menor e do maior tanque foram $12.556 \mathrm{~kg}$ e $279.040 \mathrm{~kg}$, respectivamente. Os valores da emissão atmosférica para o poluente dióxido de carbono foram obtidos do balanço obtido em laboratório, (AQMAU, 2009), onde $92 \%$, para o dióxido de carbono, $3 \%$ para o monóxido de carbono e 5\% para o material particulado. 
Tabela 2 - Dados gerados com a aplicação da Equação 1

\begin{tabular}{|c|c|c|c|c|c|c|c|c|c|c|}
\hline \multirow[b]{3}{*}{ Poluente } & \multirow[b]{3}{*}{$\underset{* * *}{\mathrm{Vol} \mathrm{Tq} \mathrm{m}^{3}}$} & \multirow[b]{3}{*}{ Vol Oper $\left(\mathrm{m}^{3}\right)$} & \multicolumn{8}{|c|}{ Combustível } \\
\hline & & & \multicolumn{3}{|c|}{ Petróleo bruto, $40^{\circ}$ API* } & \multicolumn{3}{|c|}{ Diesel** } & \multirow{2}{*}{$\begin{array}{c}\begin{array}{c}\text { Petróleo } \\
40^{\circ} \text { API }\end{array} \\
\begin{array}{c}\text { E (kg)/por } \\
\text { evento }\end{array}\end{array}$} & \multirow{2}{*}{$\begin{array}{c}\text { Diesel } \\
\text { E (kg)/por } \\
\text { evento }\end{array}$} \\
\hline & & & $\begin{array}{c}\text { Densidade } \\
\left(\mathrm{kg} / \mathrm{m}^{3}\right)\end{array}$ & $\begin{array}{l}\text { Temperatura } \\
\left({ }^{\circ} \mathrm{C}\right)\end{array}$ & $\mathrm{Fe}(\mathrm{g} / \mathrm{kg})$ & $\begin{array}{c}\text { Densidade } \\
\left(\mathrm{kg} / \mathrm{m}^{3}\right)\end{array}$ & $\begin{array}{c}\text { Temperatura } \\
\left({ }^{\circ} \mathrm{C}\right)\end{array}$ & $\mathrm{Fe}(\mathrm{g} / \mathrm{kg})$ & & \\
\hline Dióxido de Carbono (CO2) & 120.092 & 84064,4 & 825 & 15,6 & 0 & 820 & 15 & 0 & 216.936 .591 & 279.040 \\
\hline Monóxido de Carbono (CO) & 120.092 & 84064,4 & 825 & 15,6 & 30 & 820 & 15 & 0,61 & 2.080 .594 & 42.049 \\
\hline Material Particulado-MP (C ) & 120.092 & 84064,4 & 825 & 15,6 & 170 & 820 & 15 & 0,22 & 11.790 .032 & 15.165 \\
\hline Dióxido de Nitrogênio (NO2) & 120.092 & 84064,4 & 825 & 15,6 & 0 & 820 & 15 & 2,4 & 0 & 165.439 \\
\hline Dióxido de Enxofre (SO2) & 120.092 & 84064,4 & 825 & 15,6 & 0 & 820 & 15 & 2,22 & 0 & 153.031 \\
\hline Dióxido de Carbono (CO2) & 26.687 & 18680,9 & 825 & 15,6 & 0 & 820 & 15 & 0 & 48.207 .931 & 62.009 \\
\hline Monóxido de Carbono (CO) & 26.687 & 18680,9 & 825 & 15,6 & 30 & 820 & 15 & 0,61 & 462.352 & 9.344 \\
\hline Material Particulado-MP (C) & 26.687 & 18680,9 & 825 & 15,6 & 170 & 820 & 15 & 0,22 & 2.619 .996 & 3.370 \\
\hline Dióxido de Nitrogênio (NO2) & 26.687 & 18680,9 & 825 & 15,6 & 0 & 820 & 15 & 2,4 & 0 & 36.764 \\
\hline Dióxido de Enxofre (SO2) & 26.687 & 18680,9 & 825 & 15,6 & 0 & 820 & 15 & 2,22 & 0 & 34.007 \\
\hline Dióxido de Carbono (CO2) & 10.764 & 7534,8 & 825 & 15,6 & 0 & 820 & 15 & 0 & 19.444 .305 & 25.011 \\
\hline Monóxido de Carbono (CO) & 10.764 & 7534,8 & 825 & 15,6 & 30 & 820 & 15 & 0,61 & 186.486 & 3.769 \\
\hline Material Particulado-MP (C ) & 10.764 & 7534,8 & 825 & 15,6 & 170 & 820 & 15 & 0,22 & 1.056 .756 & 1.359 \\
\hline Dióxido de Nitrogênio (NO2) & 10.764 & 7534,8 & 825 & 15,6 & 0 & 820 & 15 & 2,4 & 0 & 14.828 \\
\hline Dióxido de Enxofre (SO2) & 10.764 & 7534,8 & 825 & 15,6 & 0 & 820 & 15 & 2,22 & 0 & 13.716 \\
\hline Dióxido de Carbono (CO2) & 5.404 & 3782,8 & 825 & 15,6 & 0 & 820 & 15 & 0 & 9.761 .894 & 12.556 \\
\hline Monóxido de Carbono (CO) & 5.404 & 3782,8 & 825 & 15,6 & 30 & 820 & 15 & 0,61 & 93.624 & 1.892 \\
\hline Material Particulado-MP (C ) & 5.404 & 3782,8 & 825 & 15,6 & 170 & 820 & 15 & 0,22 & 530.538 & 682 \\
\hline Dióxido de Nitrogênio (NO2) & 5.404 & 3782,8 & 825 & 15,6 & 0 & 820 & 15 & 2,4 & 0 & 7.445 \\
\hline Dióxido de Enxofre (SO2) & 5.404 & 3782,8 & 825 & 15,6 & 0 & 820 & 15 & 2,22 & 0 & 6.886 \\
\hline
\end{tabular}

Fonte: *LEMIEUX, 2004. **AQMAU, 2009. *** API Standard 650, Welded Steel Tanks for Oil Storage 


\section{CONSIDERAÇÕES FINAIS}

O objetivo deste trabalho foi desenvolver uma fórmula para o cálculo de emissões atmosféricas originadas em incêndios em tanques com petróleo e óleo diesel, e, a partir da comparação com os dados de emissões de poluentes do Estado de São Paulo analisar o impacto causado. Diante disto, o trabalho respondeu o problema de pesquisa, pois os dados proporcionam a possibilidade da comparação dos volumes emitidos, tanto no incêndio como pelos veículos. Ao analisar o relatório de emissões veiculares do Estado de São Paulo (CETESB, 2014), identificamos a emissão de 428 mil toneladas de monóxido de carbono (CO), o equivalente a $428.000 .000 \mathrm{~kg}$ de $\mathrm{CO}$ por ano. Se dividirmos este valor por 365 (dias no ano) teremos a emissão veicular diária no estado de São Paulo de (CO) equivalente a $1.172 .602 \mathrm{~kg}$. Pegamos este poluente como exemplo, pois é um dos quais temos dados de comparação disponíveis neste trabalho. Neste trabalho identificamos, no caso da queima do volume de combustível do maior tanque de armazenamento, a emissão de $2.080 .594 \mathrm{~kg}$ de $(\mathrm{CO})$, e para o menor tanque, o equivalente a $93.624 \mathrm{~kg}$ de $(\mathrm{CO})$, ambos, para um evento de incêndio, em que todo o volume queimasse até o fim, sem controle. Sendo que a quantidade de tanques envolvidos pode ser maior do que um tanque, o que elevaria volume de emissão de poluentes para atmosfera.

Conclui-se que ao compararmos a emissão veicular de $1.172 .602 \mathrm{~kg}$ de CO para todo o estado de São Paulo, contra uma emissão em um incêndio de $2.080 .594 \mathrm{~kg}$ de CO (tanque grande) e 93.624 $\mathrm{kg}$ (tanque pequeno), dependendo da duração de alguns dias de incêndio, a quantidade de poluentes emitidos para uma única localidade (uma pequena indústria em um bairro urbano), conforme as direções do vento, o volume de poluente é bastante significativo para a população local, e para aquelas atingidas em distâncias um pouco maiores, conforme a direção e intensidade do vento. Podemos concluir, também, que os efeitos à saúde podem se apresentar de bastante agravada, aguda, para a população local, durante a exposição às concentrações tão elevadas, num tempo tão curto como estas apresentadas neste trabalho para cada evento de incêndio, quando comparados com os efeitos crônicos, originados da exposição a emissões veiculares ao longo dos anos e em concentrações menores.

Entretanto, foram percebidas limitações nessa pesquisa, devido às informações identificadas na pesquisa realizada, sobre fatores de emissão, encontrou-se, somente, para alguns poluentes do petróleo bruto, como o (CO) e o (MP) e para o óleo diesel (CO), (MP), (NO2), e (SO), o que nos levou a um inventário potencial limitado, aplicados aos volumes de quatro tanques que representam a faixa do estudo proposto, apenas para a reflexão de um panorama existente e preocupante. Assim propõem-se para futuros trabalhos um desenvolvimento de pesquisas para a identificação de fatores de emissão para todos os poluentes gerados na combustão de petróleo e seus derivados, bem como os 
efeitos à saúde decorrentes de uma exposição aguda, como é o caso das emissões por incêndios em petróleo e óleo diesel. Por fim, percebe-se uma escassez de bibliografia nacional, e uma limitação para bibliografia internacional geradas de pesquisas na área de incêndios em petróleo e seus derivados, o que abre um precedente para novas pesquisas. 


\section{REFERÊNCIAS BIBLIOGRÁFICAS}

AQMAU. Review of emission factors for incident fires protecting and improving the environment in England and. Bristol: [s.n.].

CETESB. Qualidade do ar no estado de São Paulo 2013. São Paulo: 2014.

CETESB. Qualidade do Ar no Estado de São Paulo 2019. São Paulo: 2020.

CETESB. Emissões Veiculares no Estado de São Paulo 2019. São Paulo: 2020.

CONAMA. Resolução no 436/2011. p. 42, 2011.

GULLETT, B. K. et al. Characterization of emissions and residues from simulations of the Deepwater Horizon surface oil burns. Marine Pollution Bulletin, v. 117, n. 1-2, p. 392-405, 2017.

HUSAIN, T. Kuwaiti oil fires: Regional environmental perspectives. Canada: Pergamon, 1996. v. 92

KUMAR, A. et al. Non-methane hydrocarbon (NMHC) fingerprints of major urban and agricultural emission sources for use in source apportionment studies. Atmospheric Chemistry and Physics, v. 20, n. 20, p. 12133-12152, 2020.

LEMIEUX, P. M.; LUTES, C. C.; SANTOIANNI, D. A. Emissions of organic air toxics from open burning: a comprehensive review. ASTM, p. 1-32, 2004.

MMA, M. DO M. A. Resolução Conselho Nacional do Meio Ambiente no 491, 2018.

MMA; MS; MC. Compromisso pela Qualidade do Ar e Saúde Ambiental. p. 20, 2009.

NI, M. et al. A review on black carbon emissions, worldwide and in China. Chemosphere, v. 107, p. 83-93, 2014.

SHAREEF, M. M.; HUSAIN, T.; ALHARBI, B. Optimization of Air Quality Monitoring Network Using GIS Based Interpolation Techniques. Journal of Environmental Protection, v. 07, n. 06, p. 895911, 2016.

SPEIGHT, J. G. The Chemistry and Technology of Petroleum. New York: CRC press, 2014.

TIETENBERG, TT.; LEWIS, L. Environmental and Natural Resource Economics. London: Taylor \& Francis, 2018.

UNEP. The Production Gap: The discrepancy between countries' planned fossil fuel production and global production levels consistent with limiting warming to $1.5^{\circ} \mathrm{C}$ or $2^{\circ} \mathrm{CProduction}$ Gap. Paris: 2020. Disponível em: <https://www.unenvironment.org/resources/emissions-gap-report-2019>.

UNEP. Emissions Gap Emissions Gap Report 2020. Nairobi: UNEP, 2020. 